\title{
Diverticulum of the lacrimal sac associated with rhinosporidiosis
}

\author{
M MATHEW KRISHNAN, V K KAWATRA, V A RAO, AND C RATNAKAR \\ From the Department of Ophthalmology, Jawaharlal Institute of Postgraduate, Medical Education and \\ Research, Pondicherry-605006, India
}

SUMmary A rare case of diverticulum of the lacrimal sac associated with rhinosporidiosis is reported. The clinical presentation and possible pathogenesis are discussed.

Diverticulum of the lacrimal sac of sufficient size to cause clinical symptoms is rare.' It may be of congenital, inflammatory, or traumatic origin. Mycotic dacryocystitis due to rhinosporidiosis has been noted. ${ }^{2}$ Blastomycosis of the nasolacrimal duct associated with diverticulum of the lacrimal sac has been observed. ${ }^{3}$ In the present case diverticulum of the lacrimal sac associated with rhinosporidiosis is being reported.

\section{Case report}

A South Indian female aged 19 years was admitted to the Department of Ophthalmology on 28 December 1984 complaining of a swelling at the right inner canthus of three years' duration. The swelling was gradually increasing along the right lower lid. There had been epiphora with occasional blood stained discharge for the past three months.

Correspondence to M M Krishnan, FICS.

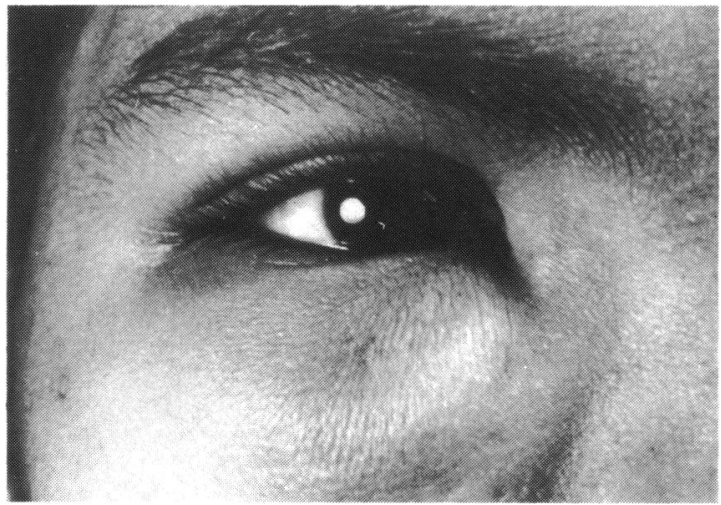

Fig. 1 Swelling of the medial canthus and the lower lid.
On examination there was a soft swelling extending from the medial canthus to the medial two-thirds of right lower orbital margin (Fig. 1). It was painless, and the surface was smooth and slippery, adherent to neither overlying skin nor underlying bone. On pressure a serosanguineous discharge came through both puncta, resulting in shrinkage of the swelling. The left eye showed no abnormality. The ears, nose, and throat were normal.

Syringing the right lacrimal passages after evacuating the discharge resulted in a tense cystic swelling with excruciating pain. The left nasolacrimal duct was patent. Dacryocystography with propyliodine (Dionosil) dye showed a diverticulum of the lacrimal sac and dye did not appear in the nose after 30 minutes (Fig. 2).

A diagnosis of diverticulum of the lacrimal sac was

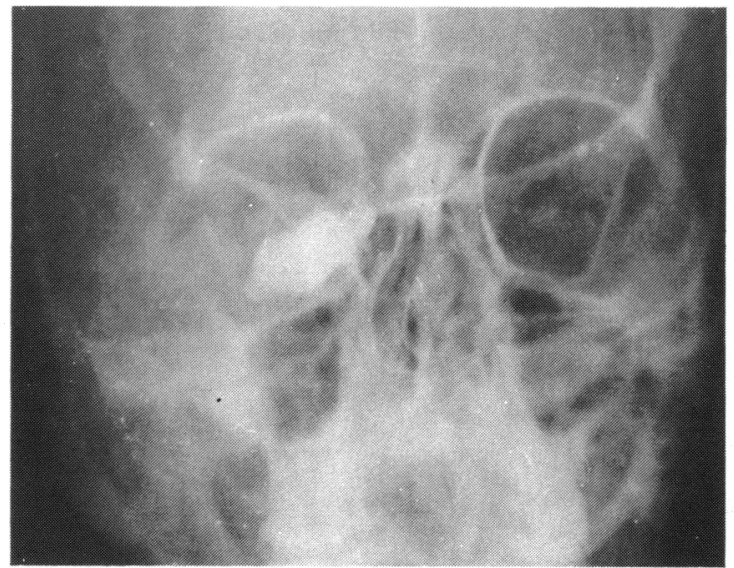

Fig. 2 Posteroanterior view of dacryocystogram showing diverticulum of the lacrimal sac. 


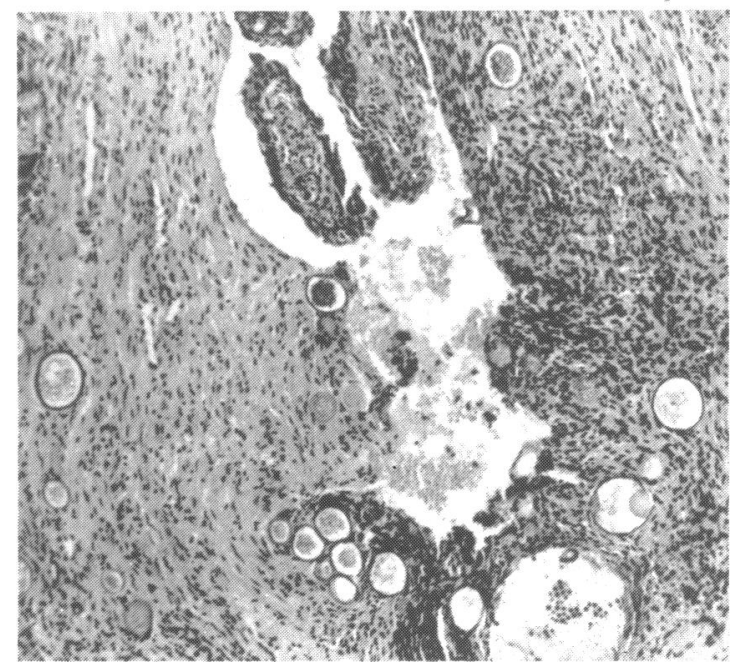

Fig. 3 Section from the diverticulum showing Rhinosporidium seeberi trophocytes and sporangia. (H and $E, \times 63)$.

made, and both diverticulum and sac were excised. Histopathological examination showed thick double walled trophocytes and sporangia of Rhinosporidium seeberi in the fibrous tissue of the sac and diverticulum (Fig. 3). Rupture of some of the sporangia had resulted in the release of spores into the wall, producing a giant cell reaction. In addition the sections showed lymphocytic and plasma cell infiltration.

\section{Discussion}

Rhinosporidiosis is a fungal infection caused by Rhinosporidium seeberi. Oculosporidiosis involves the lacrimal sac in $24 \%$ of cases, and a history of bleeding from the nose is often given. ${ }^{4}$

Diverticulum of the lacrimal sac is rare and may be of congenital, inflammatory, or traumatic origin. Either it may be in direct and free communication with the sac or the two structures may be separate." Congenital diverticula have been seen in association with obstruction of the nasolacrimal duct. ' and an intermittent obstruction of its drainage by vascular engorgements or chronic inflammation.' Diverticulum accompanied by an infection of the nasolacrimal duct by blastomycosis ${ }^{3}$ and recurrent lacrimal abscess with patency of the nasolacrimal passages" have been reported. Trauma, for instance from rough, repeated probings, may also result in a diverticulum. ${ }^{5}$

The development of the diverticula of the lacrimal sac cannot be explained solely by mechanical factors. The changes are usually congenital malformations.5 In the present case probably the following sequence of events occurred. There may have been a symptomless congenital diverticulum of the lacrimal sac with patency of passages. Rhinosporidiosis of the lacrimal passages caused intermittent obstruction by chronic inflammation and venous engorgement, resulting in retention of secretion, which presented clinically as an obvious swelling, epiphora, and blood stained discharge.

\section{References}

1 Ormrod JN. Diverticulum of the lacrimal sac. Br J Ophthalmol 1958; 42: 526-8.

2 Duke-Elder S. System of ophthalmology. London: Kimpton, 1974: 13 (2): 730-3.

3 Michail D (cited by Ormrod). Arch Ophthalmol 1932; 49: 384 .

4 Kuriakose ET. Oculosporidiosis. Br I Ophthalmol 1963; 47: $346-9$.

5 Radót M, Bölcs $S$. Acute dacryocystitis in the newborn infant. In: Veir ER, ed. The lacrimal system. Proceedings of the first international symposium. Saint Louis: Mosby, 1971: 129-30.

6 Law FW. Acute recurrent lacrymal diverticulitis. Trans Ophthalmol Soc UK 1943; 63: 295-301.

Accepted for publication II February 1986. 